\title{
Fabrication of micro-structured tools for the production of curved metal surfaces by pulsed electrochemical machining
}

\author{
Tejas Mankeekar $^{1} \cdot$ Dirk Bähre $^{2} \cdot$ Dan Durneata $^{3} \cdot$ Thomas Hall $^{2} \cdot$ Rainer Lilischkis $^{1} \cdot$ Harald Natter $^{3}$. \\ Monika Saumer ${ }^{1}$ [D
}

Received: 3 March 2021 / Accepted: 25 September 2021 / Published online: 30 October 2021

(c) The Author(s) 2021, corrected publication 2022

\begin{abstract}
A new, scalable process chain for the fabrication of curved micro-structured metallic tools is developed and evaluated. Arrays of arrows, circles, semicircles and rings with final lateral dimensions of 124 to $819 \mu \mathrm{m}$ are realised on the tools and successfully transmitted in one process step to stainless steel workpieces with a functional area of $6.5 \mathrm{~cm}^{2}$ using pulsed electrochemical machining. Photolithography-etching or micromilling are applied as initial micro-structuring processes, resulting in micro-structured master forms. These forms are copied into reusable silicon forms. This is followed by epoxy casting and electroforming to obtain the final tools. The tools are made of Nickel and have a diameter of $34 \mathrm{~mm}$. Whilst micromilling, photolithography, silicon casting, epoxy casting and electroforming copy the structures very precisely, the wet etching process induces a widening of the dimensions due to the isotropic character of the process. The advantage of the process chain is the reusability of the master as well as of the silicone forms, which can be copied very precisely and easily with scalable processes to get precision tools with relatively large micro-structured areas. The reusability of the forms makes the fabrication of micro-structured tools relatively cost-efficient. The use of photolithography as the initial structuring process enables the generation of arbitrary, user-defined geometries for the micro-structures on the tool surface. The process chain described has the potential to fabricate lateral structure sizes on tools down to one micrometre.
\end{abstract}

Keywords Micro-texturing $\cdot$ Micro-patterning $\cdot$ Photolithography $\cdot$ Etching $\cdot$ PECM $\cdot$ Precision tooling

\section{Introduction}

Micro-structuring of functional surfaces and micro-motion devices are growing research fields for manyfold applications [1, 2]. Micro-structuring is used to tailor the performance of the related macro devices by changing the physical, chemical and/or mechanical character of the surface. The applications are, e.g. in microelectronics, optics or energy conversion where electrical, optical or thermal effects are of importance [3]. The influence on wetting, adhesion or

Monika Saumer

Monika.Saumer@hs-kl.de

1 Microsystems Technology, University of Applied Sciences, Kaiserslautern, Amerikastraße 1, 66482 Zweibrücken, Germany

2 Institute of Production Engineering, Saarland University, Campus A4.2, 66123 Saarbrücken, Germany

3 Physical Chemistry, Saarland University, Campus B2 2, 66123 Saarbrücken, Germany cell growth is applied in fluidics, sensing, bioengineering or medicine $[4,5]$. By using micro-structured surfaces, a reduction of friction and wear for rolling and sliding contacts of machine elements are achieved [6-8].

Pulsed electrochemical machining (PECM) is a manufacturing process for complex shaped products with structures or surface geometries in the sub-mm range [9, 10]. In PECM, the material is removed, based on anodic metal dissolution, by applying a pulsed voltage between the anode (tool) and the cathode (workpiece). The PECM process allows high precision of the machined metallic structures, diversity of processable materials and prevention of mechanical stresses in the surface of the products [11-13]. PECM either uses cylindrical, conical, pin or disc shape electrodes as tools with diameters less than $100 \mu \mathrm{m}$, which are drilled into the workpiece to get, e.g. micro-grooves, or it uses a universal electrode tool, where the path of the tool gives the 3D space. Typically, these tools are produced by micromechanical-, laser ablation-, etching- or different-erosion techniques $[14,15]$. In [16] 
a copper sheet is used as a kind of "universal tool" to make lines and pillars on plane and convex substrates. Another option is to use "large area" electrodes where a negative design of the desired micro-structure arrays is integrated with the tool area and copied into the workpiece during the sinking process $[17,18]$. Although numerous methods for the fabrication of universal electrodes have been described and established [19,20], the production of "large area" electrodes with complicated shapes is still a challenge and individual and small series production of tools is required [17]. In [21] a gold electrode tool with a diameter of approx. $1 \mathrm{~mm}$ with micro-structures of about $500 \mu \mathrm{m}$ has been described. In [22] a "large-area" electrode $(25 \mathrm{~mm} \times 25 \mathrm{~mm})$ has been fabricated by electrodeposition, but with simple shapes. They have also shown that the original form can be reused.

In our approach for large area tool fabrication, we combine conventional, scalable micro-structuring and casting methods. In a former work we developed a new procedure for planar PECM tools and workpieces [18], starting with photolithographic structuring and ending in an electroforming procedure. Tool diameters of $100 \mathrm{~mm}$ and line structures with lateral dimensions of about $110 \mu \mathrm{m}$ have been realised and successfully copied by PECM to get planar microstructured workpieces.

An additional challenge is the micro-structuring of curved surfaces which is in principle possible with PECM, but this requires curved tools. Therefore, we adopted the aforementioned tool fabrication by changing the initial microstructuring. We start our process chain with a curved substrate (with the same inclination as the later workpiece) and use either photolithography-etching or micromilling to generate the micro-structures into the substrate. Also, all further steps need to be adapted to the curved form.

Several advantages of the aforementioned micro-structuring techniques can be applied to the fabrication of the PECM tool: Micro-structuring using photolithography and a following wet etching allows arbitrary texture designs on a reusable so called "master form". The following copying of these structures by casting into a robust polymer master, which also can be used several times for the subsequent PECM tool fabrication via electroforming, makes the tool production very cost-efficient and reproducible. Furthermore, whilst using these scalable techniques the size of the tool is not limited.

Alternatively, micromilling is used for the initial microstructuring instead of photolithography-etching, which is in some cases (simple and lower number of structures) a relatively fast process.

As a proof-of-concept stainless steel sealing rings are fabricated by PECM using curved micro-structured tools with arrows, circles, semicircles and rings in the sub-mm range. Both the quality of the individual copying processes and the overall performance of the process chain are evaluated.

Comparable curved geometries are applicable for example for cam tappets or ball and socket joints.

\section{Description of the process chain}

The process chain consists of the initial micro-structuring to develop the master form, the casting steps to produce the intermediate form for the electroforming of the PECM tool and the PECM process itself to obtain the workpiece. In Fig. 1 the individual process steps are illustrated. At the beginning, the curved substrate, with the same curvature as the final workpiece, is micro-structured using either photolithography-etching or micromilling, resulting in a master form. This is followed by two copying steps: a silicone casting and an epoxy casting. The silicone cast can be reused, whereas the epoxy cast becomes the cathode for the subsequent fabrication of the tool in the electroforming process and can only be used once. The electroformed tool in turn serves as cathode in the final PECM.

\subsection{Manufacturing of the master form}

Two approaches are used to obtain the micro-structured master forms, either photolithography followed by wet etching (arrows, circles, semicircles and rings) or micromilling (rings).

\subsubsection{Photolithography and wet etching}

Initially, the micro-structure geometry of the planar mask is transferred into the photoresist on the curved metal
Fig. 1 Process chain for micro-structuring (schematic): 1 Substrate, 2 Substrate after micro-structuring (reusable master form), 3 Silicone casting (reusable), 4 Epoxy casting, 5 PECM tool, 6 Metal workpiece, 7 Metal workpiece after microstructuring

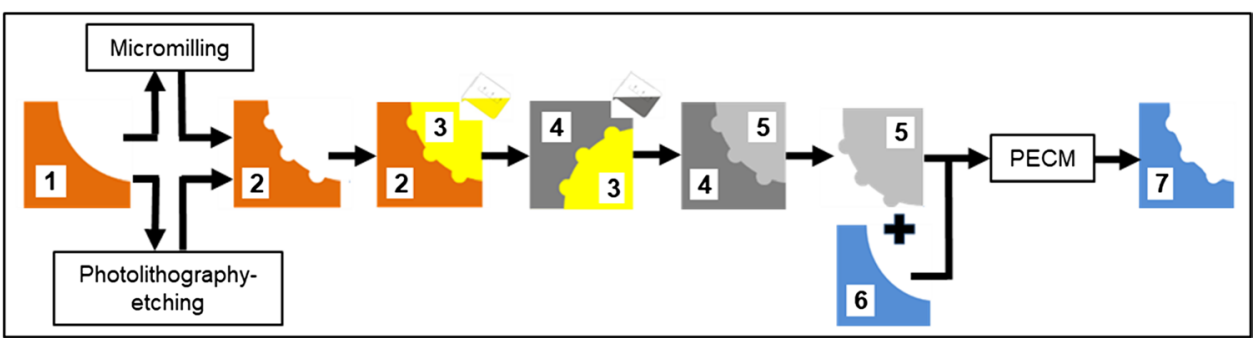


substrate using photolithography. After that, the openings in the photoresist are transferred to the metal substrate using wet chemical etching (Fig. 2A). For the photolithography process, the curved substrate is spin coated with a liquid positive photoresist (AZ 1514H, MicroChemicals GmbH, Ulm, Germany), specifically suited for adhering to metallic surfaces, using a spin coater (Reinraumtechnik Lanz, Konstanz, Germany) at $2800 \mathrm{rpm}$ for $60 \mathrm{~s}$. This is followed by a baking step in an oven at $100{ }^{\circ} \mathrm{C}$ for $10 \mathrm{~min}$ to remove most of the solvent in the photoresist and to stabilise the photoresist, resulting in a $5 \mu \mathrm{m}$ thick coating. For the exposure, a transparent glass mask coated with light blocking chromium is used, wherein the desired micro-structure geometries are left uncoated. The desired micro-structure geometry of the mask is transferred to the photoresist by a mask aligner (MA/BA 6, SÜSS MicroTec SE, Garching, Germany) in shadow mask exposure using a mercury vapour lamp (Fig. 2a) with an exposure time of $45 \mathrm{~s}$ at a set dose value of $5.9 \mathrm{~mW} / \mathrm{cm}^{2}$. The solubility of the exposed regions of the photoresist increases due to a photo-induced chemical reaction. The exposed regions are dissolved (Fig. 2b) using an alkaline developer solution (AZ $726 \mathrm{MIF}$, MicroChemicals GmbH, Ulm, Germany) for $60 \mathrm{~s}$ followed by a $60 \mathrm{~s}$ water rinse. The final photoresist structures are defined by the unexposed regions.

In the next phase, the substrate with the structured photoresist layer is etched isotropically using wet chemical etching (Fig. 2c). This is done by immersing the substrate in a $2.33 \mathrm{M} \mathrm{FeCl}_{3}$ solution at $50{ }^{\circ} \mathrm{C}$ for 15 min with constant stirring, followed by rinsing under water for $60 \mathrm{~s}$. In the final step the photoresist is stripped using acetone followed by ethanol immersion (Fig. 2d) for 5 min. Patterns with arrows, circles, semicircles and rings as micro-structure geometries are produced using this approach with planar masks of lateral structure openings in the range of $50-500 \mu \mathrm{m}$.

\subsubsection{Micromilling}

A precision micromilling machine (HSPC 2522, KERN Microtechnik GmbH, Eschenlohe, Germany) is used in a 3 axes mode for this purpose. A CAD model with the desired structure geometry and size is constructed. A much larger sized ( $\varnothing 4 \mathrm{~mm}$ ) solid carbide endmill (Karnasch Professional Tools GmbH, Heddesheim, Germany) is used at $5000 \mathrm{rpm}$ with a cutting speed of $62.83 \mathrm{~m} / \mathrm{min}$, a vertical feed of $30 \mathrm{~mm} / \mathrm{min}$ and a horizontal feed of $60 \mathrm{~mm} / \mathrm{min}(0.006 \mathrm{~mm} /$ tooth). The coolant used is WICODRAW $1433 \mathrm{~S}$ (Wilke Kühlschmiertechnik GmbH, Radolfzell am Bodensee, Germany) (Fig. 2B). Master forms with rings as structure geometry are produced using this approach with a lateral structure size of $100 \mu \mathrm{m}$.

\subsection{Casting steps}

The structured curved metal substrates (master forms) fabricated through the above-mentioned processes serve as starting points for the manufacturing of the epoxy casting which is finally required for the electroforming process. This is done in two steps. First a negative form of the structured master form is produced by casting a two-component liquid silicone rubber (ELASTOSIL® M 4601 A/B, Wacker Chemie AG, Munich, Germany). During the casting, air is evacuated from the mixture with a vacuum pump. Thus, the silicone shows fine surface details of the master. The chosen silicone is significantly elastic thereby allowing easy separation from the master and is hence reusable. As a second step, this silicone casting is used to produce the epoxy casting using a resin and hardener mix (Epoxidharz E45 and Härter E45, Chemische Erzeugnisse, Hamburg, Germany), which is poured over the negative form. The curing time is $24 \mathrm{~h}$ at room temperature $\left(25^{\circ} \mathrm{C}\right)$. Hereby fine surface details down to a structure size of a few $\mu \mathrm{m}$ are replicated. To protect the surface of the epoxy form from dust and to avoid crack formation, the epoxy piece is stored at room temperature $\left(25^{\circ} \mathrm{C}\right)$ by immersing it in distilled water until further use.

\subsection{Electroforming process of the PECM tool}

An electroless nickel plating method is used to create a conductive layer on the epoxy casting for the subsequent electroforming. In step one, the epoxy surface is activated using a palladium $(0.1 \mathrm{~g} / \mathrm{L})$ and hydrochloric acid solution

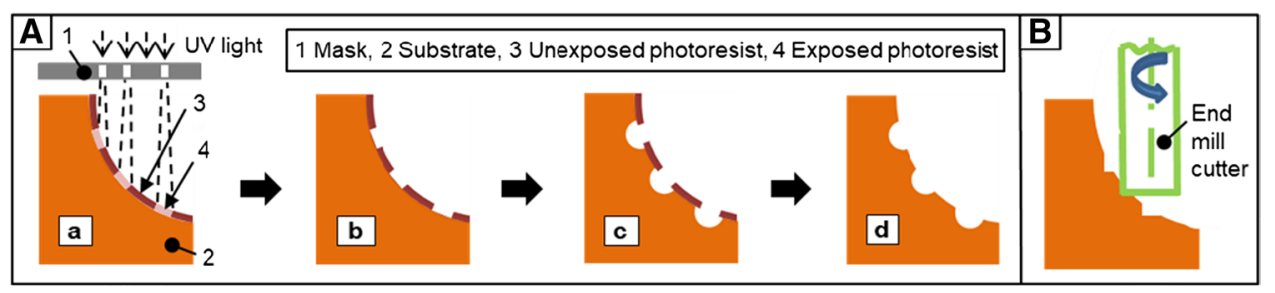

Fig. 2 Initial micro-structuring processes (schematic) A Photolithography-etching: substrate a during exposure, b after developing the photoresist (red), $\mathbf{c}$ after wet chemical etching and $\mathbf{d}$ after photoresist stripping; B micromilling process. The vertical distance between the top and bottom edges of the curved substrate surface is $4.3 \mathrm{~mm}$. (colour figure online) 
at room temperature $\left(25^{\circ} \mathrm{C}\right)$. Step two involves rinsing with distilled water so that the excess Pd solution is removed. In the third step, the surface is coated with a thin ( $\mu \mathrm{m}$ range) nickel layer using a commercial electrolyte (Sigma Aldrich) by electroless deposition. The Nickel coated epoxy casting is then electrically connected and coated via electroplating in a nickel sulfamate electrolyte bath (Grüssing $\mathrm{GmbH}$, Filsum, Germany) at $25^{\circ} \mathrm{C}$ and $3.8 \mathrm{pH}$ to produce the PECM tool. The two-electrode setup of this electroforming process consists of the Ni coated epoxy casting as the working electrode (cathode) and a nickel-bead filled mesh as the sacrificial anode. A deposition rate of $8 \mu \mathrm{m} / \mathrm{h}$ is achieved for a current density of $20 \mathrm{~mA} / \mathrm{cm}^{2}$ using a pulsed current. To achieve a stable nickel tool, a shell thickness of $1 \mathrm{~mm}$ is necessary resulting in a total electrodeposition time of about 5 days. At the end, the nickel PECM tool (shell) is removed from the epoxy casting by heating it in a water bath $\left(90-100^{\circ} \mathrm{C}\right)$ and partially breaking open the epoxy casting. Then this shell is filled with molten bismuth to deliver a completely solid PECM tool with sufficient mechanical stability which also enables good current distribution during the PECM microstructuring process.

\subsection{PECM micro-structuring}

The micro-structuring of the workpiece is performed using an industrial PECM machine system (PEMCenter8000, PEMTec SNC, Forbach, France). A $\mathrm{NaNO}_{3}$ based electrolyte at $20^{\circ} \mathrm{C}, \mathrm{pH} 8$, with an electrical conductivity of $100 \mathrm{mS} / \mathrm{cm}$ is used. The electrolyte is fed from the lower side through the centre of the metal workpiece into the working gap. For the reliable transfer of the tool shape and its micro-structure, a removal height of $0.5 \mathrm{~mm}$ is required. The PECM is performed with a feed rate of $0.3 \mathrm{~mm} / \mathrm{min}$, an applied voltage of $12 \mathrm{~V}$, a vibration frequency of $50 \mathrm{~Hz}$ with a pulse on-time of $5 \mathrm{~ms}$ and an electrolyte pressure of $3 \mathrm{bar}$. The anode sample material is stainless steel. Figure 3 shows the machining setup with a PECM tool and the corresponding workpiece.

\subsection{Measuring equipment}

Each state in the process chain is characterised using a scanning electron microscope (SEM) (SUPRA 40, Carl Zeiss AG, Oberkochen, Germany). The silicone and epoxy castings are gold sputtered in order to be imaged using SEM. An optical microscope (Axioplan 2, Carl Zeiss Microscopy $\mathrm{GmbH}$, Jena, Germany) is used for imaging and measuring the photolithography masks. Contact perthometry (MarSurf XR/XT20, Mahr, Göttingen, Germany) measurements are performed using a stylus with a $2 \mu \mathrm{m}$ tip radius and $90^{\circ}$ opening angle in order to compare the primary surface of the master form, the micro-structure profiles of the nickel PECM tool and the stainless steel workpiece after PECM

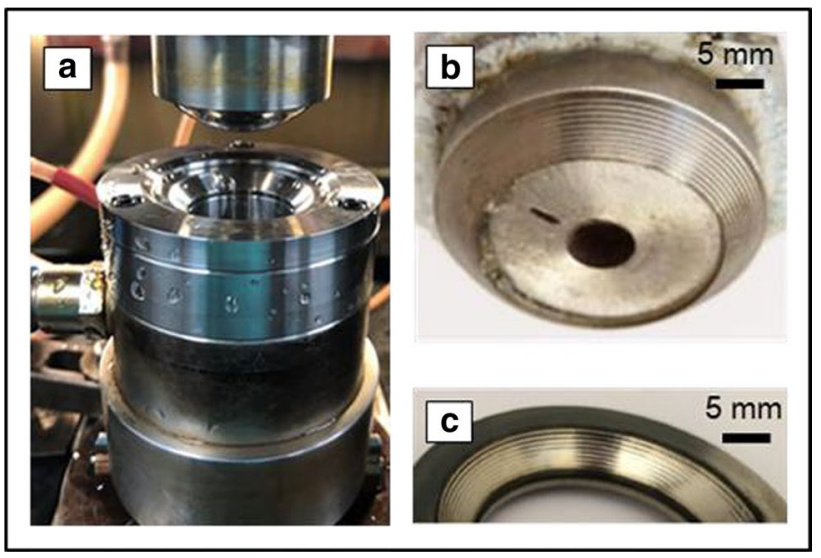

Fig. 3 a PECM process chamber, b nickel PECM tool microstructured and $\mathbf{c}$ metal workpiece after micro-structuring

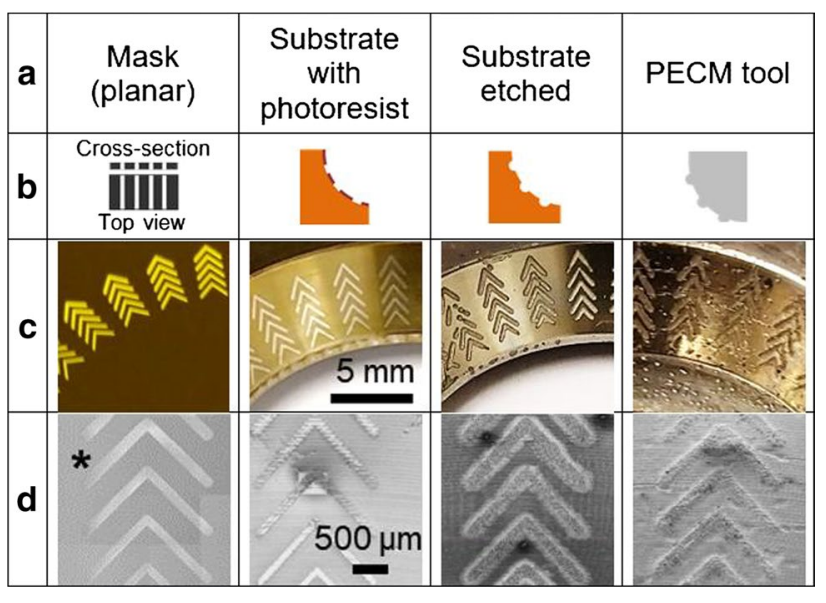

Fig. 4 Micro-structures over the photolithography-etching process chain, arrows as example: a process state, $\mathbf{b}$ schematic cross-section, c digital camera, d SEM, *Optical microscope

micro-structuring. Overview imaging of each state is done using a 13 MP digital camera.

\section{Results and discussion}

\subsection{Process chains for the tool fabrication}

The change in micro-structure geometries and lateral dimensions (widths) over the process chain are investigated using digital camera and SEM. The photographs and SEM images in Fig. 4 show the top views of the substrates at different stages within the process chain. In case of the photolithography-etching process chain, each type of micro-structure geometry is copied precisely from the mask to the photoresist structures, whereas a widening of the etched structures on the master form (substrate etched) can be observed. The 
following copying processes (two casting steps and electroforming) resulting in the PECM tool replicate the structures very precisely without further widening. Also in case of micromilling as initial micro-structuring step, the structure transfer from the master form to the PECM tool takes place without any significant change in width (Fig. 5).

For a more precise evaluation, the widths of the structures are measured using SEM images. In Fig. 6 the measurement strategy is illustrated. Due to the curvature of the substrate the SEM top view does not give the real lateral dimensions. As this radius of curvature is large compared to the overall substrate geometry, the surface is approximated to be flat. To arrive at the real lateral size of the micro-structures a $45^{\circ}$ inclination of the substrate surface with respect to the horizontal plane is considered. Hence, the real lateral structure sizes on the inclined substrate are calculated as $41 \%$ larger

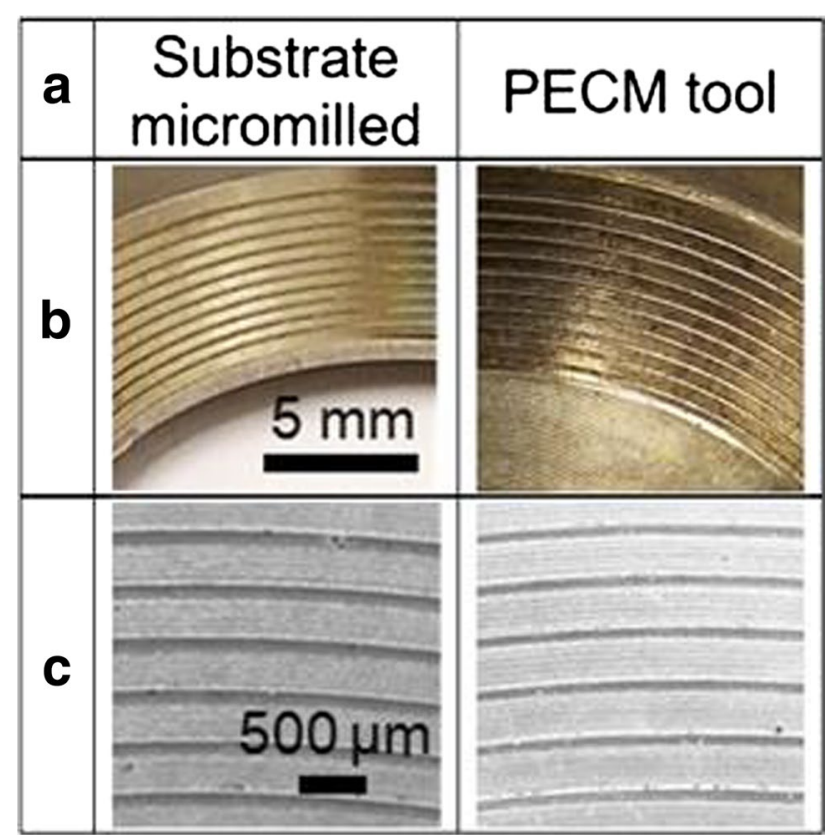

Fig. 5 Micro-structures over the micromilling process chain, rings: a process state, $\mathbf{b}$ digital camera, $\mathbf{c}$ SEM than the measured lateral structure sizes received from the top view of the SEM images. The measured values from the top view as well as the corrected values considering the inclination can be found in Table 1 .

For photolithography the measured values of the resist openings from the top view have the same lateral dimensions $(42$ to $501 \mu \mathrm{m})$ as the structures on the plane mask ( 50 to $500 \mu \mathrm{m}$ ) with low standard deviation (smaller structures 2 to $12 \%$ and large structures 2 to $4 \%$ ) showing good accuracy and reproducibility of the photolithography process. The inclination results in a widening of the photoresist structures, giving corrected lateral dimension in the range of 59 to $703 \mu \mathrm{m}$.

The next step is wet etching, which is isotropic for metal substrates. Therefore, a so called underetching is expected, which means in our case during the etching process the lateral dimensions of the openings, defined by the photoresist are broadened. The longer the etching time, the deeper the etched structures and the broader the lateral dimensions. In our case a depth of about 40 to $50 \mu \mathrm{m}$ is desired. The etch rate, determined by preliminary tests with plane substrates, is about $3 \mu \mathrm{m} / \mathrm{min}$. Therefore, we etched for $15 \mathrm{~min}$ and estimated an underetching of about $40 \mu \mathrm{m}$ on each side, which would result in a broadening of the lateral dimension of about $80 \mu \mathrm{m}$. As can be seen in Table 1 the actual underetching and the derived etching rate is different, depending on the type of structures. It is similar for circles and semicircles (approx. $3 \mu \mathrm{m} / \mathrm{min}$ ), higher for rings (approx. $4 \mu \mathrm{m} /$ $\mathrm{min}$ ) and highest for arrows (approx. $6 \mu \mathrm{m} / \mathrm{min}$ ). This is due to different fluidic conditions for the etching solution for different shapes of openings.

The metal substrate after photolithography and etching is the master form. As a result of these two process steps the micro-structure size of the master form compared to the structure size of the plane mask is widened due to the inclination of the substrate and the isotropic character of the wet etching. The degree of underetching depends on the etching time and the geometry of the structures. For example, the $100 \mu \mathrm{m}$ mask structures result in inclined structures in the master form of $215 \mu \mathrm{m}$ (circles) to $307 \mu \mathrm{m}$
Fig. 6 Measurement illustration for values in Table 1 . a, c Process, $\mathbf{b}$ schematic of the measurement method (Top view width: solid lines) and evaluation method (Real width: dotted lines), d SEM pictures of the structures with measurement location (yellow region) and direction of measurement (red line). (colour figure online)

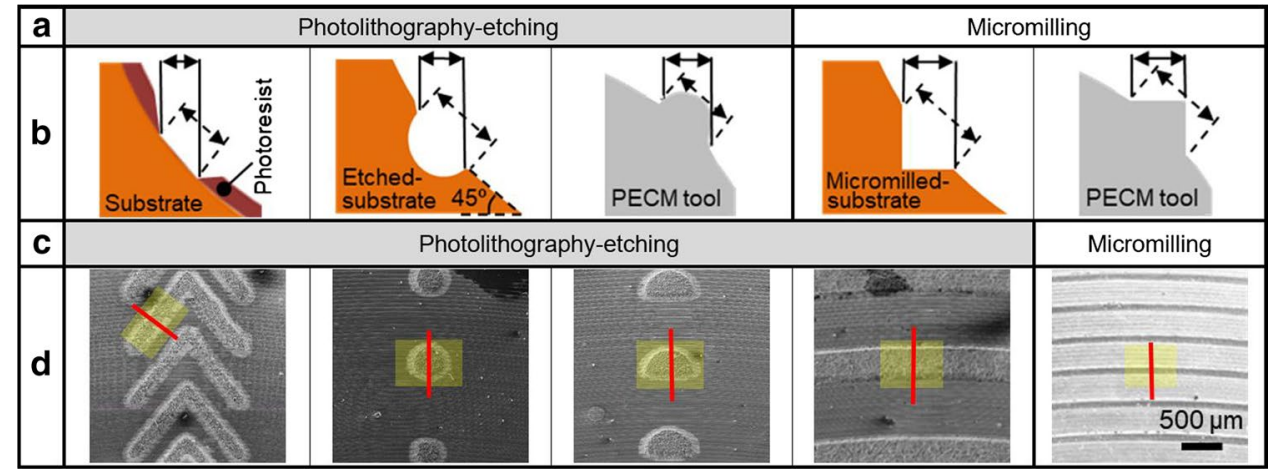


Table 1 Dimensional change of the micro-structures over the process chain: A photolithography-etching and $\mathbf{B}$ micromilling (width \pm standard deviation, $n$ number of measurements)

\begin{tabular}{|c|c|c|c|c|c|c|c|c|}
\hline \multirow[t]{2}{*}{ A } & \multirow{2}{*}{$\begin{array}{l}\text { Planar structures of } \\
\text { the mask } \\
\text { Top view width }(\mu \mathrm{m})\end{array}$} & \multicolumn{2}{|c|}{$\begin{array}{l}\text { Photoresist structures on the } \\
\text { substrate }\end{array}$} & \multicolumn{3}{|c|}{$\begin{array}{l}\text { Etched structures in the substrate (reusable } \\
\text { master form) }\end{array}$} & \multirow{2}{*}{$\begin{array}{l}\text { PECM tool with } \\
\text { structures } \\
\begin{array}{l}\text { Real width } \\
(\mu \mathrm{m})\end{array}\end{array}$} & \multirow[t]{2}{*}{$\mathrm{n}$} \\
\hline & & $\begin{array}{l}\text { Top view width } \\
(\mu \mathrm{m})\end{array}$ & $\begin{array}{l}\text { Real width } \\
(\mu \mathrm{m})\end{array}$ & $\begin{array}{l}\text { Real width } \\
(\mu \mathrm{m})\end{array}$ & $\begin{array}{l}\text { Under-etching } \\
(\mu \mathrm{m})\end{array}$ & $\begin{array}{l}\text { Etch rate } \\
(\mu \mathrm{m} / \mathrm{min})\end{array}$ & & \\
\hline \multirow[t]{2}{*}{ Arrows } & 100 & $96 \pm 8$ & $136 \pm 11$ & $307 \pm 18$ & 86 & 5.7 & $303 \pm 17$ & 6 \\
\hline & 150 & $140 \pm 3$ & $198 \pm 4$ & $380 \pm 16$ & 91 & 6.1 & $373 \pm 11$ & 6 \\
\hline \multirow[t]{3}{*}{ Circles } & 100 & $89 \pm 2$ & $126 \pm 3$ & $215 \pm 10$ & 45 & 3.0 & $223 \pm 8$ & 4 \\
\hline & 300 & $301 \pm 9$ & $426 \pm 13$ & $513 \pm 25$ & 44 & 2.9 & $506 \pm 25$ & 4 \\
\hline & 500 & $501 \pm 9$ & $709 \pm 13$ & $808 \pm 17$ & 49 & 3.3 & $819 \pm 14$ & 4 \\
\hline \multirow[t]{3}{*}{ Semicircles } & 100 & $104 \pm 3$ & $147 \pm 4$ & $231 \pm 16$ & 42 & 2.8 & $233 \pm 8$ & 4 \\
\hline & 300 & $302 \pm 8$ & $427 \pm 11$ & $518 \pm 25$ & 45 & 3.0 & $503 \pm 24$ & 4 \\
\hline & 500 & $497 \pm 12$ & $703 \pm 17$ & $803 \pm 20$ & 50 & 3.3 & $802 \pm 14$ & 4 \\
\hline \multirow[t]{3}{*}{ Rings } & 50 & $42 \pm 5$ & $59 \pm 7$ & $177 \pm 17$ & 59 & 3.9 & $171 \pm 18$ & 4 \\
\hline & 100 & $103 \pm 7$ & $146 \pm 10$ & $276 \pm 10$ & 65 & 4.3 & $264 \pm 8$ & 4 \\
\hline & 300 & $296 \pm 11$ & $419 \pm 16$ & $556 \pm 33$ & 69 & 4.6 & $550 \pm 33$ & 4 \\
\hline B & \multicolumn{3}{|l|}{ CAD } & \multicolumn{5}{|c|}{$\begin{array}{l}\text { Micromilled structures in the substrate } \\
\text { (reusable master form) }\end{array}$} \\
\hline Rings & \multicolumn{3}{|l|}{100} & \multicolumn{3}{|l|}{$126 \pm 41$} & $124 \pm 34$ & 10 \\
\hline
\end{tabular}

(arrows) for an etching time of $15 \mathrm{~min}$. Reducing the etching time to $3 \mathrm{~min}$ would result in lateral dimensions of $160 \mu \mathrm{m}$ (circles) to $170 \mu \mathrm{m}$ (arrows) in the master form. The underetching effect results in lateral dimensions of the structures from 177 to $808 \mu \mathrm{m}$.

The transfer of the structures from the master form to the PECM tool needs silicon and epoxy casting followed by the electroforming process. For all design types and sizes, the lateral dimensions are copied very precisely, as can be seen in Table 1. The standard deviations of the master form structures compared to the PECM tool structures are also similar. Therefore, the lateral dimensions of the structures on the tools range from 171 to $819 \mu \mathrm{m}$.

The micromilled structures on the master form are transferred well from the substrate to the tool (mean values 126 and $124 \mu \mathrm{m}$, respectively), but the standard deviation of the structure dimensions is very large, which can be seen in the related tool structures. This is attributed to the limitations of the centring accuracy during the milling process caused by the substrate geometry. However, the limitation of the micromilling process is the limited number of possible user-defined geometries.

The good copying quality of the process chain is also demonstrated in Fig. 7, where the grooves in the initial substrate created by the turning process can be seen as copies in both the master and the corresponding PECM tool. The lateral dimensions of these turning grooves are about $1.3 \mu \mathrm{m}$. Not only the micro-structures produced, but also the turning grooves are copied very precisely into the

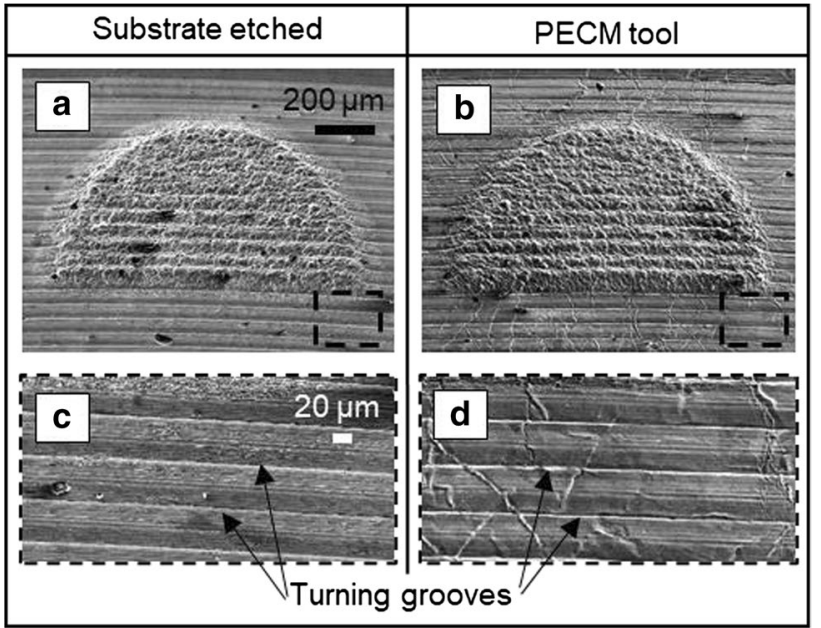

Fig. 7 SEM images of the semi-circles and turning grooves as an example of the: a, $\mathbf{c}$ etched substrate (master form) (indentations), $\mathbf{b}$, d corresponding PECM tool (elevated structures)

PECM tool. This shows the potential of the process chain to transfer structures down to one micrometre.

\subsection{PECM tools and workpieces}

The transfer quality of the structures from the PECM tools to the stainless steel workpieces can be seen in Fig. 8 for circles, arrows and rings (micromilled). The individual geometries for each PECM machined workpiece are recognisable, but the edges are rounded. The rounding of 


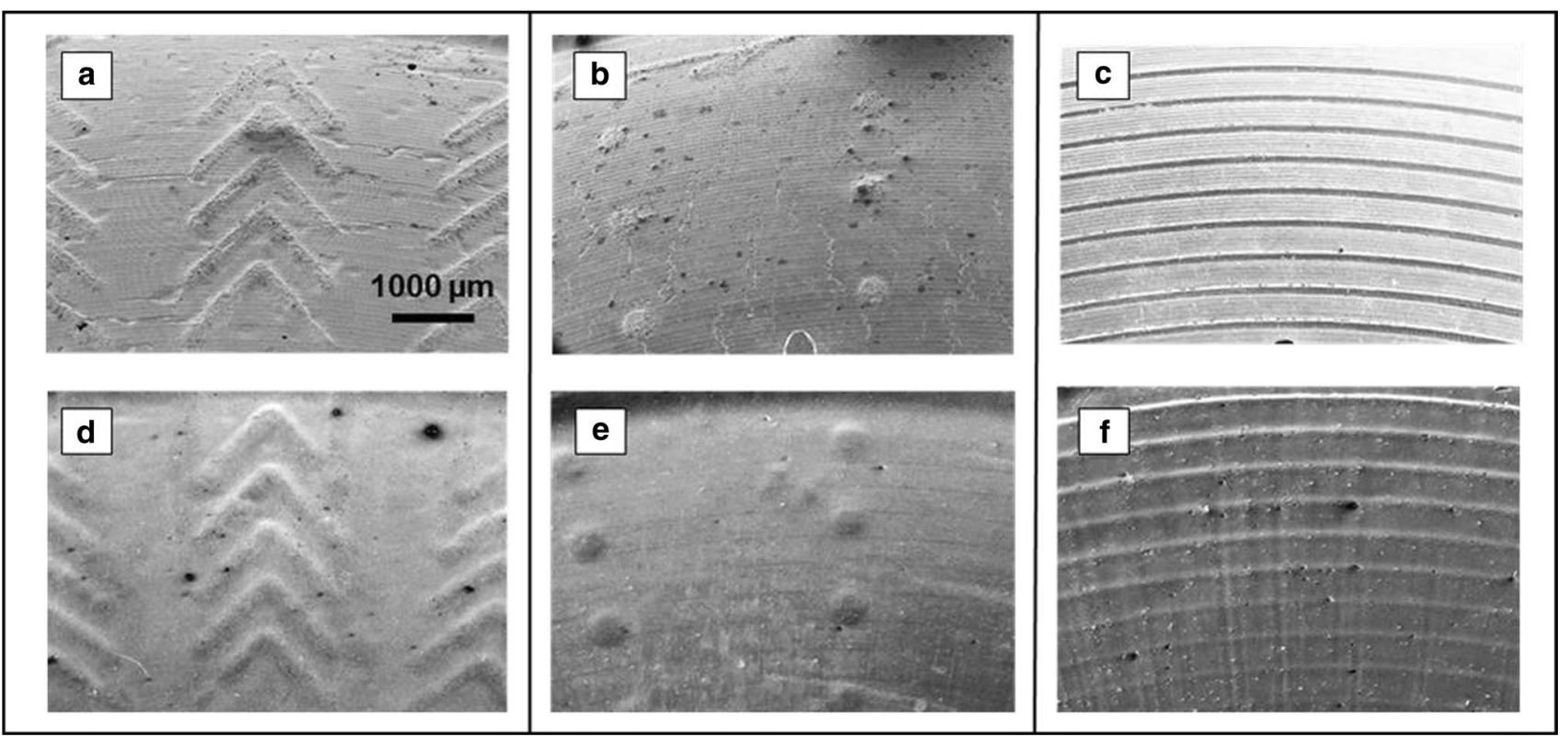

Fig. 8 SEM images of the PECM tools (elevated structures): $\mathbf{a}$ arrows, $\mathbf{b}$ circles, $\mathbf{c}$ rings (micromilled) and the micro-structured workpieces after PECM (indentations): $\mathbf{d}$ arrows, $\mathbf{e}$ circles, $\mathbf{f}$ rings (micromilled)

edges is an intrinsic effect of the PECM process [20]. The rounded edges make it difficult to measure the lateral micro-structure size using SEM. As an alternative, contact profilometry is used to capture the structure profiles of the PECM tool and the machined workpiece. This is possible for rings since they can be scanned along any radial path. Other geometries are either not radially oriented (arrows) or are too small (circles, semicircles) to be positioned along the stylus path.
Figure 9a shows the measurement plan for the contact profilometry. For the micromilled rings three traces, $120^{\circ}$ apart, are recorded for both the PECM tool and the workpiece. Figure $9 \mathrm{~b}$ shows a scan of the PECM tool and the workpiece. The original curved shape of these scans has been fitted to a straight line by the software. The tool exhibits sharp, defined micro-structures as expected to be transferred from the original micromilled master form. The corresponding micro-structures transferred to the workpiece

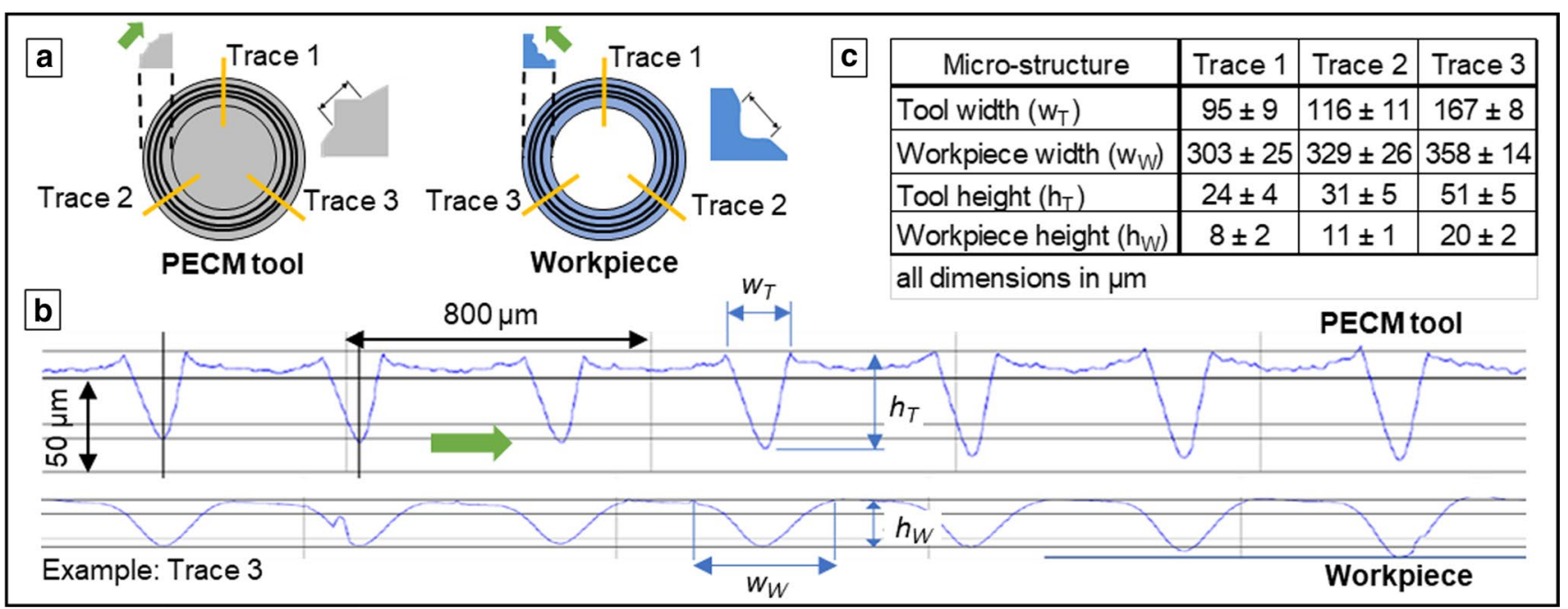

Fig. 9 a Measurement method for tool and workpiece (schematic), b contact profilometry scans of the micro-structures (rings) on the PECM tool and on the PECM processed workpiece, $\mathbf{c}$ comparison of tool and workpiece micro-structure size. $n=7$ measurements per trace, green arrow $=$ measurement direction. (colour figure online) 
show significant edge rounding, width widening and height reduction after PECM. The functional surface (between the individual microstructures) of the workpiece also looks smoother after PECM than that of the PECM tool. This is verified by comparing the roughness measurements with the profilometer on an unstructured master form $\left(R_{\mathrm{a}} 1.13 ; R_{\mathrm{z}}\right.$ $5.35)$, a PECM tool $\left(R_{\mathrm{a}} 1.15, R_{\mathrm{z}} 5.71\right)$ and a workpiece $\left(R_{\mathrm{a}}\right.$ $\left.0.51, R_{\mathrm{z}} 1.48\right)$. Unstructured samples were used here as they offer larger functional areas and thus allow surface roughness measurements. It can be further observed that the surface roughness of the master form (generated by the turning process) and the PECM tool are similar (Fig. 7), indicating a transfer of the micro-grooves generated by the turning process. A comparison of the widths and heights of the microstructures from traces 1,2 and 3 shows an increase in width of $104 \mu \mathrm{m}, 107 \mu \mathrm{m}$ and $96 \mu \mathrm{m}$ for traces 1 to 3, respectively, on each side of the micro-structure, whilst the height reduction ranges from 62 to $67 \%$ for the three traces (Fig. 9c).

\section{Conclusion and outlook}

A new process chain for the fabrication of curved microstructured metallic precision tools is designed and tested. Theoretically, a micro-structured master form can be used directly as a PECM tool for a long time. However, PECM tools wear out more quickly if there is unintentional physical contact with the workpiece during the production process. Therefore, it makes sense to copy the micro-structured master form and use the copy in production. The three-stage transfer process via a reusable silicone cast and an epoxy cast ensures that the low-cost copy can be used and the elaborately produced micro-structured master form remains physically intact. In addition, the individual process steps are scalable and thus the tool size or the number of tools produced in parallel (derived from one master form) is not limited. Recently, there is a tendency to develop machines that use several PECM tools in parallel in order to process larger areas quickly. The reusability of the silicone cast makes multiple production of the PECM tool very cost-effective.

The available dimensions on the tool depend on the performance of the initial micro-structuring methods as well as on the micro-structure geometry. Minimal lateral structure sizes of $171 \mu \mathrm{m}$ for rings, of $223 \mu \mathrm{m}$ for circles, $233 \mu \mathrm{m}$ for semicircles and of $303 \mu \mathrm{m}$ for arrows are achieved using photolithography-etching as initial micro-structuring methods. Using micromilling, $124 \mu \mathrm{m}$ structures for rings have been realised on the tool. The micro-structure designs are transferred very well by the PECM process, but the lateral micro-structure dimensions are widened by about $100 \mu \mathrm{m}$ on each side, resulting in smallest micro-structure sizes on the workpieces of about $330 \mu \mathrm{m}$.
From the results of this work the processable minimum lateral dimensions of the process chain can be estimated. The photolithography is limited due to the available, adhesionstable resist in combination with shadow exposure on inclined surfaces and results in about $50 \mu \mathrm{m}$ lateral dimensions. Subsequent time-dependent wet chemical etching widens the microstructures. The higher the desired depth, the wider the structure becomes. The following casting and electroforming steps copy the micro-structure very precisely. In our work a higher aspect ratio was desired, resulting in minimal lateral dimensions of $171 \mu \mathrm{m}$. At lower aspect ratios, lateral dimensions of less than $100 \mu \mathrm{m}$ can be achieved for the micro-structures on the precision tool.

Using other initial micro-structuring techniques to obtain the reusable master even smaller lateral dimensions are possible. We have used micromilling and realised a minimal lateral dimension of $124 \mu \mathrm{m}$ for rings, wherein the disadvantage is the restricted possibility of arbitrary structuring. Pulsed laser techniques [23-27] or soft lithography with a structured polymer membrane [28] are capable of micro-structuring curved surfaces with the smallest dimensions of approximately $36 \mu \mathrm{m}$ and in the sub- $\mu \mathrm{m}$ scale, respectively. The following casting and electroforming steps would copy the micro-structures accurately, so that no further widening of the dimensions on the final tool would occur.

Acknowledgements The authors gratefully acknowledge Erik Engelmann and Christian Neu for technical support during micromilling and for manufacturing supporting components. Additionally, the authors would like to thank the German Federal Ministry for Economic Affairs and Energy (BMWi) for financial support. We would like to dedicate this paper to PD Dr. Harald Natter, our cherished colleague, who sadly passed away during this project.

Author contributions DB, HN and MS developed the idea of the study. TM, TH, DD, DB and MS participated in its design and coordination. TM, DD, TH and MS helped to draft the manuscript. RL contributed to the acquisition and interpretation of data and provided critical review. All authors read and approved the final manuscript.

Funding Open Access funding enabled and organized by Projekt DEAL. This project work was funded within the ZIM program of the German Federal Ministry for Economic Affairs and Energy (BMWi) (Grant Number ZF4260302WO7).

Data availability The measurement data are available from the corresponding author on request.

Code availability Not applicable.

\section{Declarations}

Conflict of interest Not applicable.

Open Access This article is licensed under a Creative Commons Attribution 4.0 International License, which permits use, sharing, adaptation, distribution and reproduction in any medium or format, as long 
as you give appropriate credit to the original author(s) and the source, provide a link to the Creative Commons licence, and indicate if changes were made. The images or other third party material in this article are included in the article's Creative Commons licence, unless indicated otherwise in a credit line to the material. If material is not included in the article's Creative Commons licence and your intended use is not permitted by statutory regulation or exceeds the permitted use, you will need to obtain permission directly from the copyright holder. To view a copy of this licence, visit http://creativecommons.org/licenses/by/4.0/.

\section{References}

1. Tawfick S, De Volder M, Copic D, Park SJ, Oliver CR, Polsen ES, Roberts MJ, Hart AJ (2012) Engineering of micro- and nanostructured surfaces with anisotropic geometries and properties. Adv Mater 24(13):1628-1674. https://doi.org/10.1002/adma.20110 3796

2. Ouyang PR, Tjiptoprodjo RC, Zhang WJ, Yang GS (2008) Micro-motion devices technology: the state of arts review. Int J Adv Manuf Technol 38(5):463-478. https://doi.org/10.1007/ s00170-007-1109-6

3. Kempers R, Robinson A, Lyons A (2009) Characterization of metal micro-textured thermal interface materials. In: 2009 15th International Workshop on Thermal Investigations of ICs and Systems, 7-9 October 2009, pp 210-215

4. Limongi T, Tirinato L, Pagliari F, Giugni A, Allione M, Perozziello G, Candeloro P, Di Fabrizio E (2016) Fabrication and applications of micro/nanostructured devices for tissue engineering. Nano-Micro Lett 9(1):1. https://doi.org/10.1007/ s40820-016-0103-7

5. Qian T, Wang Y (2010) Micro/nano-fabrication technologies for cell biology. Med Biol Eng Comput 48(10):1023-1032. https:// doi.org/10.1007/s11517-010-0632-z

6. Rosenkranz A, Grützmacher PG, Gachot C, Costa HL (2019) Surface texturing in machine elements-a critical discussion for rolling and sliding contacts. Adv Eng Mater 21(8):1900194. https:// doi.org/10.1002/adem.201900194

7. Echávarri Otero J, de la Guerra OE, Bellón Vallinot I, Chacón Tanarro E (2017) Optimising the design of textured surfaces for reducing lubricated friction coefficient. Lubr Sci 29(3):183-199. https://doi.org/10.1002/ls.1363

8. Liu J, Xiang H, Fu B, Zhao Y, Zhang Z, Mou M (2019) Research on the friction and wear properties of surface micro-texture steel ring of CVT metal belt. In: 2019 IEEE 28th International Symposium on Industrial Electronics (ISIE), 12-14 June 2019, pp 1937-1943. https://doi.org/10.1109/ISIE.2019.8781260

9. Rajurkar KP, Zhu D, McGeough JA, Kozak J, De Silva A (1999) New developments in electro-chemical machining. CIRP Ann 48(2):567-579. https://doi.org/10.1016/S0007-8506(07)63235-1

10. Rebschläger A, Kollmannsperger R, Bähre D (2014) Video based process observations of the pulse electrochemical machining process at high current densities and small gaps. Procedia CIRP 14:418-423. https://doi.org/10.1016/j.procir.2014.03.105

11. Schubert N, Schneider M, Michaelis A (2014) Electrochemical machining of cemented carbides. Int J Refract Metal Hard Mater 47:54-60. https://doi.org/10.1016/j.ijrmhm.2014.06.010

12. Haisch T, Mittemeijer E, Schultze JW (2001) Electrochemical machining of the steel $100 \mathrm{Cr} 6$ in aqueous $\mathrm{NaCl}$ and $\mathrm{NaNO} 3$ solutions: microstructure of surface films formed by carbides. Electrochim Acta 47(1):235-241. https://doi.org/10.1016/S00134686(01)00561-8

13. Datta M, Landolt D (1983) Electrochemical saw using pulsating voltage. J Appl Electrochem 13(6):795-802. https://doi.org/10. 1007/BF00615829
14. Jain VK, Chauhan AS, Thakur A, Sidpara A (2013) Fabrications of micro tools and micro patterns by electrochemical micromachining and some investigation into overpotential. J Adv Manuf Syst 12(02):85-106. https://doi.org/10.1142/s0219686713500054

15. Das AK, Saha P (2013) Analysis on fabrication of micro-tools by micro-electrochemical machining process. Int J Nanomanuf 9(1):66-76. https://doi.org/10.1504/ijnm.2013.052882

16. Patel DS, Jain VK, Shrivastava A, Ramkumar J (2019) Electrochemical micro texturing on flat and curved surfaces: simulation and experiments. Int J Adv Manuf Technol 100(5):1269-1286. https://doi.org/10.1007/s00170-016-9700-3

17. Skoczypiec S (2016) Discussion of ultrashort voltage pulses electrochemical micromachining: a review. Int J Adv Manuf Technol 87(1):177-187. https://doi.org/10.1007/s00170-016-8392-z

18. Weinmann MWO, Bähre D, Munief W, Saumer M, Natter H (2014) Photolithography-electroforming-pulse electrochemical machining: an innovative process chain for the high precision and reproducible manufacturing of complex microstructures. Int J Electrochem Sci 9:3917-3927

19. Jo CH, Kim BH, Chu CN (2009) Micro electrochemical machining for complex internal micro features. CIRP Ann 58(1):181184. https://doi.org/10.1016/j.cirp.2009.03.072

20. Wang S, Zhu D, Zeng Y, Liu Y (2011) Micro wire electrode electrochemical cutting with low frequency and small amplitude tool vibration. Int J Adv Manuf Technol 53(5):535-544. https://doi. org/10.1007/s00170-010-2835-8

21. Eva FTG (2009) The machining of large areas with electrochemical micromilling. In: International Symposium on Electro Chemical Machining Technology INSECT 2009. Fraunhofer Verlag (Applied Electrochemistry in Material science), pp 59-64

22. Hernández P, Campos D, Socorro P, Benítez A, Ortega F, Díaz N, Marrero MD (2015) Electroforming applied to manufacturing of microcomponents. Procedia Eng 132:655-662. https://doi.org/ 10.1016/j.proeng.2015.12.544

23. Shamsul Baharin Ahmad F, Ghazali Mariyam J, Juyana AW (2016) Laser surface texturing and its contribution to friction and wear reduction: a brief review. Ind Lubr Tribol 68(1):57-66. https://doi.org/10.1108/ILT-05-2015-0067

24. Vilhena LM, Sedlaček M, Podgornik B, Vižintin J, Babnik A, Možina J (2009) Surface texturing by pulsed Nd: YAG laser. Tribol Int 42(10):1496-1504. https://doi.org/10.1016/j.triboint.2009. 06.003

25. Ernst AHT, Frank A, Derouach H, Bähre D (2019) Microstructuring of inconel 718 via pulse electrochemical machining. In: Paper presented at the International Symposium on Electro Chemical Machining Technology INSECT 2019, Saarland University, 14 \& 15 November 2019

26. Boidi G, Grützmacher PG, Kadiric A, Profito FJ, Machado IF, Gachot C, Dini D (2021) Fast laser surface texturing of spherical samples to improve the frictional performance of elasto-hydrodynamic lubricated contacts. Friction 9(5):1227-1241. https://doi. org/10.1007/s40544-020-0462-4

27. Bruening S, Hennig G (2015) Surface structuring of metals and non-metals for printing tools and embossing dies with an ultrafast ps-laser machining system, vol 9351. SPIE, Bellingham

28. Paul KE, Prentiss M, Whitesides GM (2003) Patterning spherical surfaces at the two-hundred-nanometer scale using soft lithography. Adv Funct Mater 13(4):259-263. https://doi.org/10.1002/ adfm.200304255

Publisher's note Springer Nature remains neutral with regard to jurisdictional claims in published maps and institutional affiliations. 